\title{
Development and Application of Coated Fertilizer in
}

\section{Japan}

\author{
Hiroshi Aoki ${ }^{1}$ and Yuichi Sekiguti ${ }^{1}$ \\ 1. JCAM AGRI Co., LTD., Tokyo 1010041, Japan
}

\begin{abstract}
The fertilizer industry faces a continuing challenge to improve its products to increase the fertilizer use efficiency and to minimize any possible adverse environmental impact. For this purpose, studies on the development of coated fertilizers have been done all over the world. In this paper, we are to introduce our coated urea "MEISTER" as the sophisticated fertilizer, with explaining the features and applications in actual fields. "MEISTER" is the coated urea with a mixture of polyolefin and silicate mineral. "MEISTER" has two releasing types. One is the linear type. Another is the sigmoidal type. Release of nitrogen from "MEISTER" mainly depends on temperature which allows precise prediction of nutrient release. Application experiments for rice, Chinese cabbage and long onion are introduced in this paper. Every experiment shows single basal application is possible by using "MEISTER" with keeping yield and high nitrogen recovery. Coated fertilizers show accurate release control of nutrients. The use of coated fertilizers brings: (a) efficient use of fertilizer resources, (b) reduction of environmental load by fertilizer, (c) labor saving. Thus applying coated fertilizers is definitely smart fertilization technology in agriculture. Coated fertilizers seem to closely meet the requirements of an ideal fertilizer. The problem is its high price compared to the normal rapid soluble fertilizer. Unit price of coated fertilizer is expensive on the surface, though total application cost of coated fertilizers is often cheaper than the cost of rapid soluble fertilizers. This sometime disturbs the spread of coated fertilizers. So, we have been trying to make an effort to reduce production cost and doing application enlargement trials of coated fertilizers for becoming more widespread. Through those studies and development, we believe coated fertilizers will contribute to agriculture more in the world.
\end{abstract}

Key words: Coated fertilizer, release control, rice, Chinese cabbage, long onion, co-situs, nitrogen use efficiency.

\section{Introduction}

Fertilizer materials have contributed to food production for many years. At the same time, the fertilizer industry faces a continuing challenge to improve its products to increase the fertilizer use efficiency, particularly nitrogenous fertilizers, and to minimize any possible adverse environmental impact [1]. For this purpose, studies on the development of coated fertilizers have been done all over the world. According to the coating materials, the fertilizers are divided into three groups: sulfur-coated, thermosetting resin coated, and thermoplastic resin coated fertilizers. Table 1 shows the invention and development of

Corresponding author: Hiroshi Aoki, Master of Environmental Science, research field: Soil Science and Plant Nutrition. coated fertilizer until 1989 [2].

At present (2017), main producers and its plants are located in North America, West European, Israel, China and Japan. Total capacities of coated fertilizer are estimated more than 3,000,000 t a year. Especially, Chinese companies rapidly increase their capacity.

In Japan, studies on the development of coated fertilizers were started almost 50 years ago and a variety of coated fertilizers have been manufactured. The production quantity was around $60,000 \mathrm{t}$ in 1995 and reached more over 100,000 $\mathrm{t}$ in 2014 (Fig. 1) [3]. Especially, coated fertilizer is very popular and used more than $35 \%$ of the paddy field with diffusion of fertilizer drill rice transplanters (Fig. 2) [4].

In this paper, we are to introduce our coated urea "MEISTER" as the sophisticated fertilizer, with explaining the features and applications in actual fields to contribute to the development of agriculture. 


\subsection{Composition and Type of "MEISTER"}

\section{Materials}

In the late 1976, we started manufacturing polyolefin-coated compound fertilizers "NUTRICOTE" as the first nutrient-releasing controlled fertilizer in the world [5]. Polyolefin-coated urea "MEISTER" followed suit in 1980. We have been developed and manufactured a variety of the nutrient releasing controlled fertilizers for various crops with different purposes by a full use of our coated technology.
The structure of "MEISTER" is presented in Photo 1. Granular urea $(2-4 \mathrm{~mm})$ is coated with a mixture of polyolefin and silicate mineral $(10 \%$ wt./wt. against urea). The thickness of membrane is $40-60 \mu \mathrm{m}$. Specifically designed coating machine is used for the film coating with the highest uniformity in thickness.

There are two releasing types for "MEISTER". One is linear type. Nitrogen is released almost linearly from the start to dissolve $80 \%$ of urea into water. Its

Table 1 Development of coated fertilizer.

\begin{tabular}{|c|c|c|c|c|c|}
\hline \multicolumn{2}{|c|}{ Type } & Company & Year & & Detail \\
\hline \multirow{10}{*}{\multicolumn{2}{|c|}{ Sulfer Coat }} & \multirow{3}{*}{ TVA USA) } & 1961 & Coated Urea & Trial(Bench Scale) \\
\hline & & & 1968 & Coated Urea & Trial(Pilot Plant) \\
\hline & & & 1978 & Coated Urea & Demonstration Plant \\
\hline & & Lesco Inc.(USA) & 1978 & Coated Urea, Coated NPK & Producing " LESCO ${ }^{\circledR} "$ \\
\hline & & IC I UK） & 1972 & Coated Urea & Selling "Gold $N^{\circledR /}$ \\
\hline & & C IL Canada ) & 1975 & Coated Urea & Taking over from IC I \\
\hline & & \multirow{2}{*}{ Mitsui- Touatsu(Japan) } & 1975 & Coated NPK & Registration in Japan \\
\hline & & & 1982 & Coated Urea & Registration in Japan \\
\hline & & \multirow{2}{*}{ O.M.SCOTT(USA) } & 1981 & Coated Urea, Coated Potash & Pilot \\
\hline & & & 1983 & Coated Urea, Coated Potash & Full Schale Production \\
\hline \multirow{13}{*}{$\begin{array}{l}\text { Resin } \\
\text { Coat }\end{array}$} & \multirow{8}{*}{$\begin{array}{l}\text { Thermo } \\
\text { setting } \\
\text { Resin }\end{array}$} & ADM(USA) & 1964 & Coated NPK & Trial \\
\hline & & SCC(USA) & 1967 & Coated NPK & Producing " 0 smocote ${ }^{\circledR}$ " \\
\hline & & Syouwadenkou(Japan) & 1970 & Coated NPK & Registration as " $\mathrm{CSR}^{\circledR}$ " in Japan \\
\hline & & \multirow{2}{*}{ Syouwakasei(Japan) } & 1984 & Coated NPK & Registration in Japan \\
\hline & & & 1988 & Coated NPK & Registration as "Showcoat ${ }^{\circledR}$ " in Japan \\
\hline & & \multirow{2}{*}{ Central Glass(Japan) } & 1979 & Coated NPK & Registration in Japan \\
\hline & & & 1988 & Coated Urea, Coated NPK & Registration as "Seracoat ${ }^{\circledR}$ " in Japan \\
\hline & & SAG(West Germany) & 1982 & Coated NPK & " PLANTACOTE ${ }^{\circledR} "$ \\
\hline & \multirow{5}{*}{$\begin{array}{l}\text { Thermo } \\
\text { plastic } \\
\text { Resin }\end{array}$} & Asahi- Kasei(Japan) & 1976 & Coated NPK & Registration as "Long ${ }^{\circledR}$ " in Japan \\
\hline & & Chisso(Japan) & 1980 & Coated Urea & Registration as "LP coat ${ }^{\circledR}$ " in Japan \\
\hline & & Nissan Chemical(Japan) & 1984 & Coated NPK & Registration in Japan \\
\hline & & Sumit omo Chemical(Japan) & 1989 & Coated NPK & Registration in Japan \\
\hline & & Kyouwahakkou(Japan) & 1989 & Coated NPK & Registration in Japan \\
\hline
\end{tabular}

Fujita, T., Maeda, S., Shibata, M., and Takahashi, T., 1989. Resarch and development of coated fertilizers, In proceeding Symposium on fertilizers- present and future, Japanese Society of Soil Science and Plant Nutrition, 111-126 


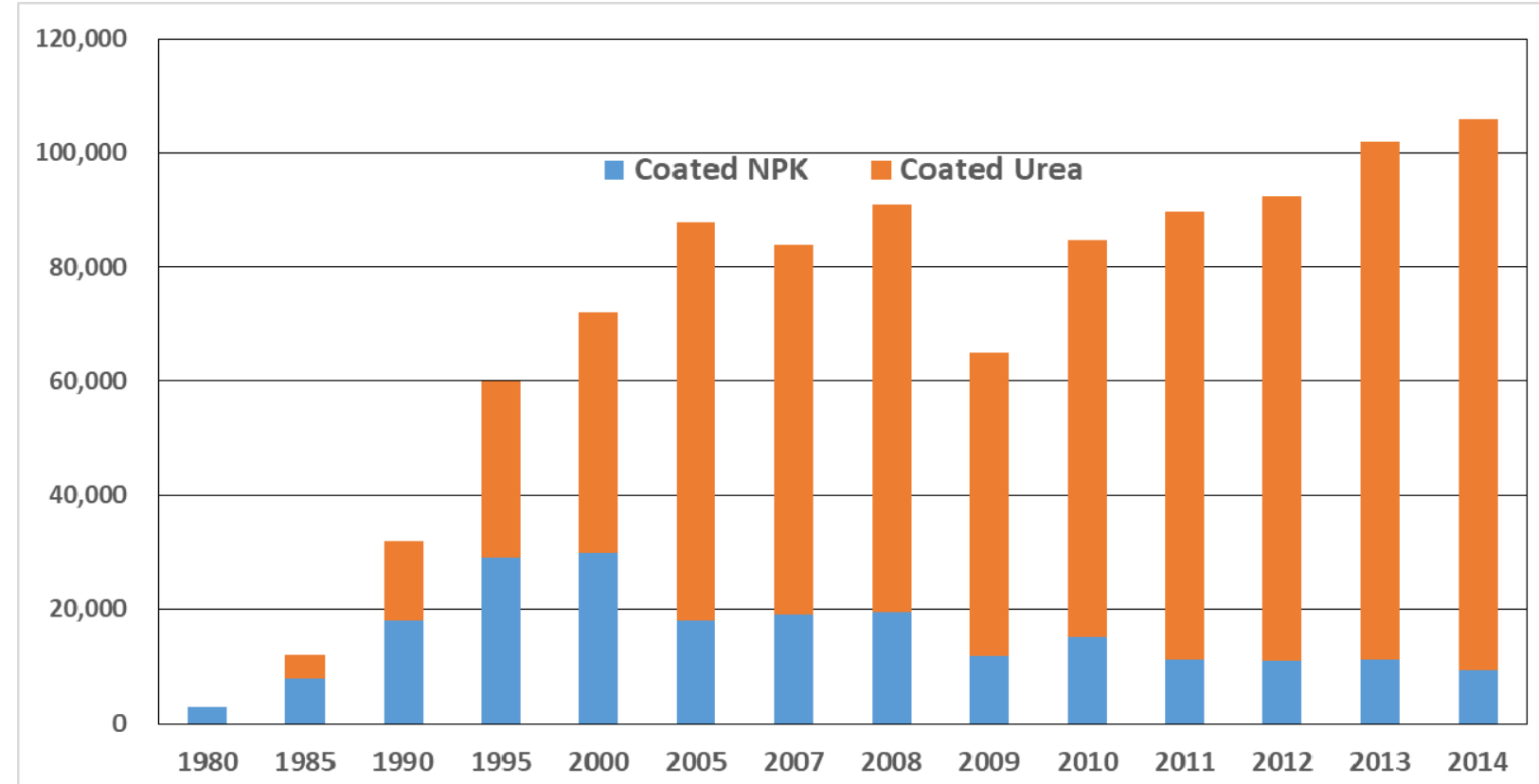

Fig. 1 Production of coated fertilizer in Japan.

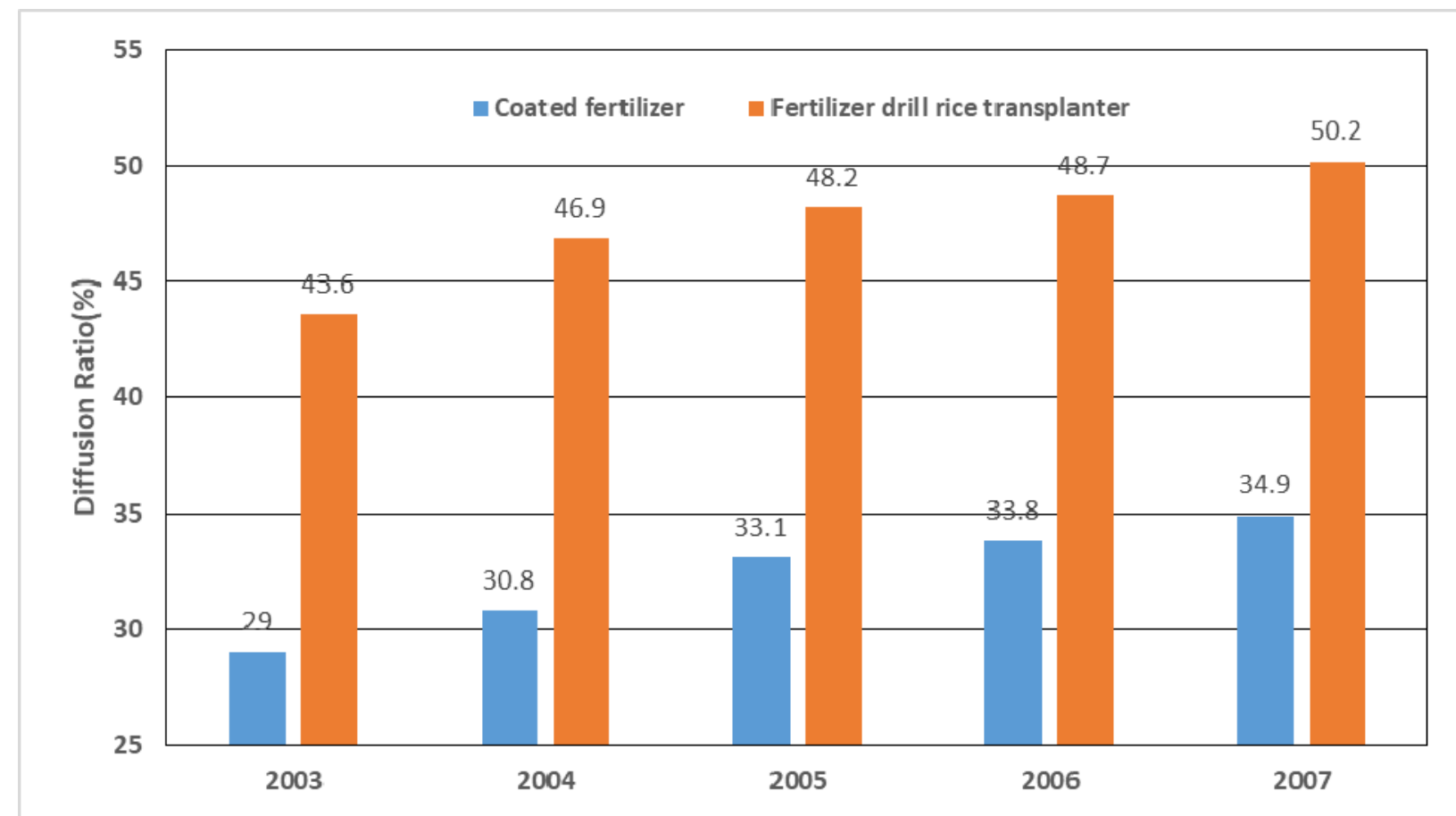

Fig. 2 Diffusion ratio of fertilizer drill rice transplanter and coated fertilizer in rice cultivation in Japan. 


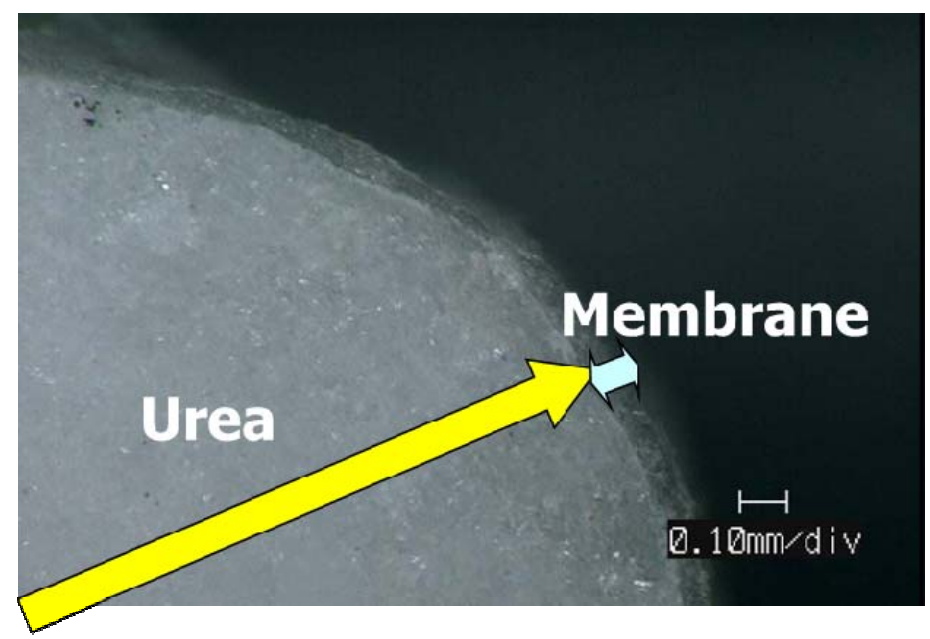

Photo 1 Cross section of MEISTER granule.

longevities are from 30 to 360 days at $25{ }^{\circ} \mathrm{C}$ (Fig. 3).

Total nitrogen content is $42 \%$. The other is sigmoidal type. This type has a lag period of 20 to 100 days and release period of 20 to 100 days after lag period at $25^{\circ} \mathrm{C}$ (Fig. 3). Its total nitrogen content is $41 \%$.

\subsection{Releasing Mechanism of "MEISTER"}

Fig. 4 describes the segment releasing mechanism of "MEISTER". At first, moisture is taken into the particle through the membrane of "MEISTER". Next, the water taken in through membrane dissolves internal fertilizer. Then, the water pressure in the "MEISTER" particle is increased and urea solution leaks out through the membrane.

From the releasing mechanism, the releasing rate of "MEISTER" is influenced by temperature. The temperature affects the rate of water vapor permeability through the membrane. Other soil properties such as $\mathrm{pH}$, texture, soil moisture (if it is not below $30 \%$ of field capacity) and so on don't affect the releasing so much.

After knowing the soil temperature, we can simulate the releasing longevity by using the computer. We can choose the coated fertilizer type and longevity coping with plant's nutrition demand. Fig. 5 is the example that shows the preferable "MEISTER" blend for strawberry cultivation in Kyushu Japan and its simulated release by the computer.

\subsection{Efficiency of "MEISTER" in the Field}

Due to the release pattern, the nitrogen release from "MEISTER" is usually synchronized with growth rate of crops. "MEISTER" is lasting nitrogen supply. So, recovery of this fertilizer by the crop is much higher than that of a rapid soluble one. Relation between the fertilizer treatment and nitrogen use efficiency (NUE) is shown Fig. 6 [6]. The NUE of "MEISTER" is more than twice of ammonium sulfate because of its controlled releasing nutrients as crops demand. In particular, co-situs application proved the highest efficiency of nitrogen use over $80 \%$, and this is a strong proof "MEISTER" is superior to existing conventional fertilizer in not only labor saving, but also economic and environmental viewpoint.

\subsection{Features of Coated Urea "MEISTER"}

Summarizing the feature of the coated urea "MEISTER", we can point out 4 advantages to compare with conventional fertilizers. These are based on high NUE of "MEISTER".

First of all, it is "easy fertilization". NUE of "MEISTER" is very high so that farmers can reduce application times and rate by using "MEISTER". Only one time basal application is also possible because nitrogen needed for whole growth of crops can be applied at one time without salt injury. It's very easy for farmers. 


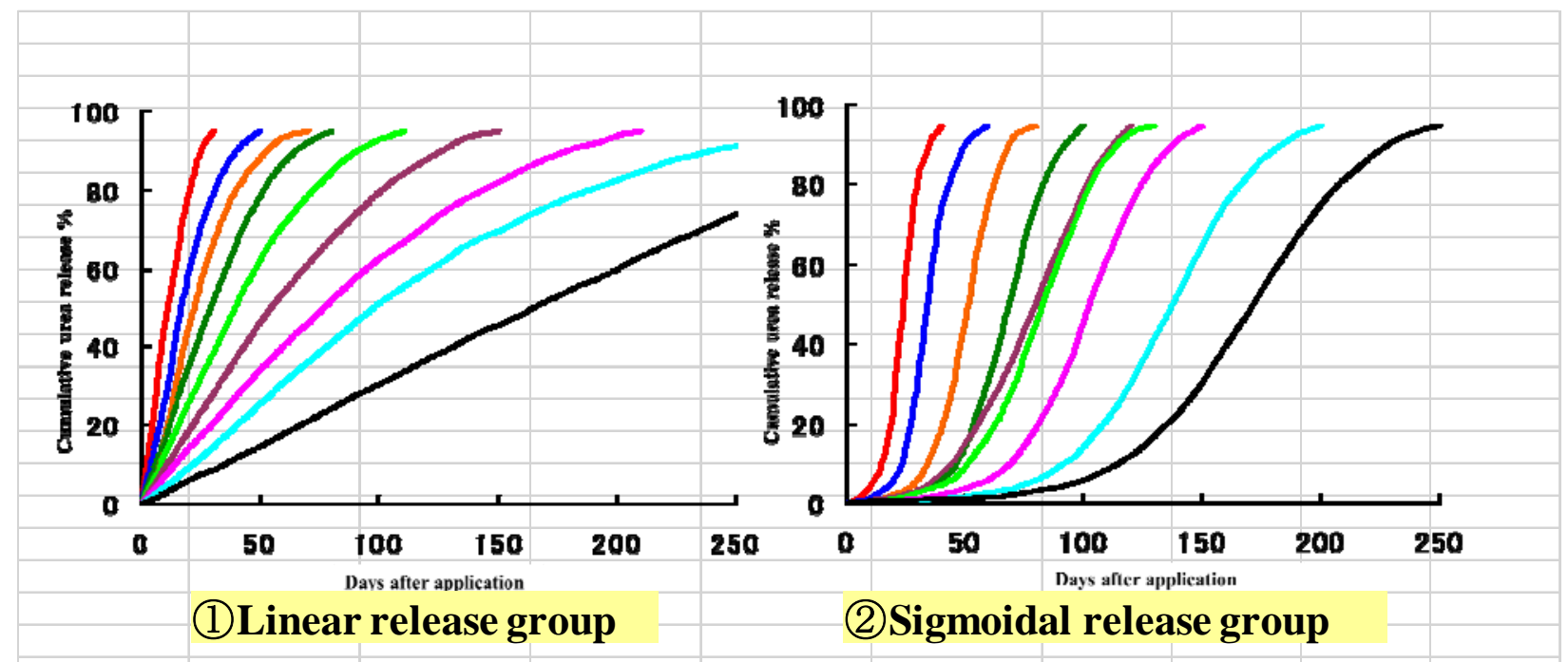

Fig. 3 Nitrogen release of MEISTER in water at $25^{\circ} \mathrm{C}$.

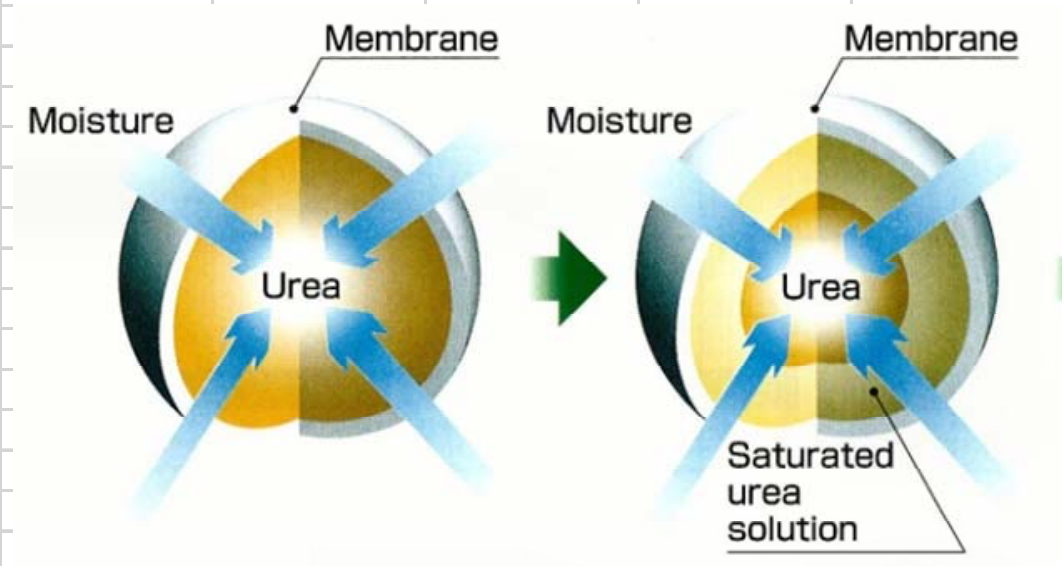

(1)Water Adsorption (2Dissolution of Urea

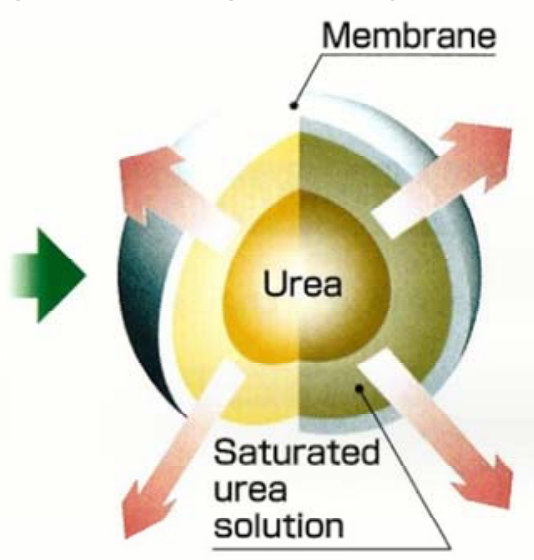

(3)Leaching

Fig. 4 Segment release MECHANIZM of “MEISTER”.

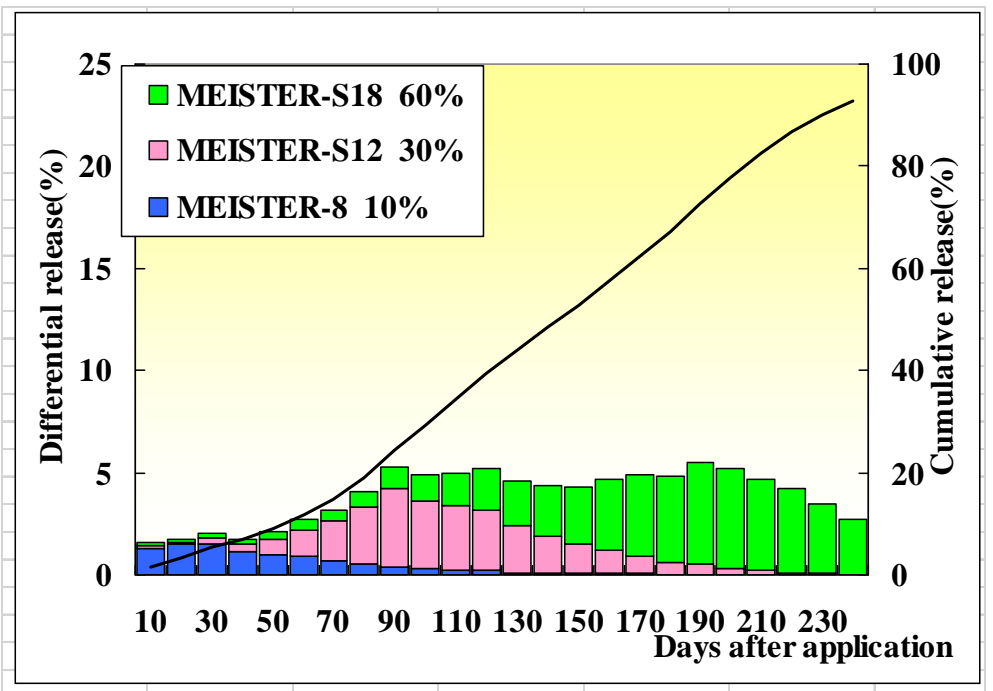

Fig. 5 Releasing simulation of "MEISTER" blend for strawberry in Kyusyu. 


\begin{tabular}{|c|c|c|c|c|}
\hline & & & \\
\hline
\end{tabular}

Fig. 6 Relation between applied position and nitrogen efficiency.

The second is "low production cost". Reducing the application times and quantity makes labor saving. Though the price of coated fertilizer is usually more expensive than conventional fertilizers, total fertilizer cost of "MEISTER" including labor cost, fertilizer application cost and so on is often lower from conventional fertilizers.

The third is "releasing simulation". Release of nitrogen from "MEISTER" is not affected by soil properties such as $\mathrm{pH}$, texture, soil moisture (if it is not below $30 \%$ of maximum water holding capacity), oxidation-reduction potential, ionic strength of the soil solution and so on. Release mainly depends on temperature which allows precise prediction of nutrient release over time. After knowing the soil temperature, we can simulate the releasing longevity by using the computer. We can choose the "MEISTER" type and longevity coping with plant's nutrition demand.

At last, it is "lower environmental pollution". Increasing the recovery of nitrogen from "MEISTER" by crops means less nitrogen entering into the environment. Large uptake by crop makes leaching to underwater decrease. In addition, reducing the application quantity may decrease nitrous oxide gas emission at least equivalent value of reducing quantity.

\section{Application of Coated Urea "MEISTER" and Blended Fertilizer "MEISTER-MX"}

"MEISTER" is the coated urea. It contains only the nitrogen. So, we usually blend "MEISTER" with compound fertilizers or/and single fertilizer to apply the actual field. Blend composition is considered in the condition of crops, temperature and cultivation field. We name blended one "MEISTER-MX".

"MEISTER" and "MEISTER-MX" are extensively applied to a variety of crops in Japan where the labor cost of farming is rapidly rising. In this section, we introduce the application experiments of rice, Chinese cabbage and long onion in Japan.

\subsection{Rice}

Otsuka studied the single basal application of "MEISTER" for rice in Saga prefecture Japan [7]. In this study, three species of rice (Yumeshizuka, Hinohikari and Hiyokumochi) were evaluated at the Saga agricultural research center in 2015. Fertilizer was applied by a transplanter with side row fertilizing machine. The former cultivation of rice was the barley and its fertilizer dosage was N:P:K $=120: 57: 86 \mathrm{~kg} / \mathrm{ha}$.

The fertilizer dosage and the growth data of each treatment are in Table. 2. Only nitrogen was applied. "MEISTER" was sigmoidal type. Depending on the 
Table 2 Nitrogen fertilizer treatment and growth of rice.

\begin{tabular}{|c|c|c|c|c|c|c|c|}
\hline Rice Species & Treatment & $\begin{array}{l}\text { N Dosage, } \\
\mathrm{kg} / \mathrm{ha}\end{array}$ & \begin{tabular}{|l} 
Earing \\
Day
\end{tabular} & Mature Day & $\begin{array}{l}\text { Culm } \\
\text { Lengt }\end{array}$ & $\begin{array}{l}\text { No. of } \\
\text { Ears, }\end{array}$ & \begin{tabular}{|l|} 
Ear \\
length,cm
\end{tabular} \\
\hline \multirow{5}{*}{ Yumeshizuku } & No Fertilizer & 0 & Aug.17 & Sep.29 & 85.0 & 302 & 17.5 \\
\hline & Conventional & 50 & Aug.16 & Sep.30 & 87.5 & 338 & 18.2 \\
\hline & MEISTER S 100 & 22 & Aug.16 & Sep.29 & 85.4 & 300 & 17.7 \\
\hline & MEISTER S 100 & 29 & Aug.16 & Sep.29 & 86.3 & 314 & 17.6 \\
\hline & MEISTER S 100 & 44 & Aug. 16 & Sep.30 & 86.7 & 323 & 18.0 \\
\hline \multirow{5}{*}{ Hinohikari } & No Fertilizer & 0 & Aug.31 & Oct.11 & 73.7 & 308 & 17.2 \\
\hline & Conventional & 90 & Aug.29 & Oct.14 & 81.6 & 414 & 17.6 \\
\hline & MEISTER SS 100 & 28 & Aug.30 & Oct.12 & 77.2 & 326 & 18.1 \\
\hline & MEISTER SS 100 & 49 & Aug. 30 & Oct.13 & 78.9 & 344 & 18.6 \\
\hline & MEISTER SS 100 & 71 & Aug.29 & Oct.14 & 81.9 & 364 & 19.4 \\
\hline \multirow{5}{*}{ Hiyokumochi } & No Fertilizer & 0 & Sep.9 & Oct.26 & 63.9 & 359 & 17.1 \\
\hline & Conventional & 140 & Sep.10 & Oct.31 & 67.4 & 443 & 19.5 \\
\hline & MEISTER S 120 & 49 & Sep. 9 & Oct.29 & 65.0 & 397 & 18.4 \\
\hline & MEISTER S 120 & 82 & Sep.10 & Oct.29 & 65.6 & 416 & 18.4 \\
\hline & MEISTER S 120 & 105 & Sep.10 & Oct.31 & 66.0 & 414 & 18.9 \\
\hline
\end{tabular}

Table 3 Yield and nitrogen recovery rate.

\begin{tabular}{|l|l|l|r|r|r|r|r|}
\hline Rice Species & Treatment & $\begin{array}{l}\text { N Dosage, } \\
\mathrm{kg} / \mathrm{ha}\end{array}$ & $\begin{array}{l}\text { Straw, } \\
\mathrm{kg} / \mathrm{ha}\end{array}$ & $\begin{array}{l}\text { Brawn Bice, } \\
\mathrm{kg} / \mathrm{ha}\end{array}$ & $\begin{array}{l}\text { Ratio, } \\
\%\end{array}$ & $\begin{array}{l}\text { Thousand } \\
\text { Kernel, g }\end{array}$ & $\begin{array}{l}\text { N Recover } \\
\text { Rate, \% }\end{array}$ \\
\hline \multirow{5}{*}{ Yumeshizuku } & No Fertilizer & 0 & 5,820 & 5,020 & & 23.7 & \\
\cline { 2 - 8 } & Conventional & 50 & 6,560 & 5,730 & $100 \%$ & 23.5 & 28 \\
\cline { 2 - 8 } & MEISTER S100 & 22 & 6,230 & 5,270 & $92 \%$ & 23.4 & 53 \\
\cline { 2 - 8 } & MEISTER S100 & 29 & 6,600 & 5,660 & $99 \%$ & 23.7 & 66 \\
\cline { 2 - 8 } & MEISTER S100 & 44 & 6,730 & 5,620 & $98 \%$ & 23.8 & 55 \\
\hline \multirow{5}{*}{ Hinohikari } & No Fertilizer & 0 & 7,690 & 4,520 & & 22.8 & \\
\cline { 2 - 8 } & Conventional & 90 & 8,140 & 5,700 & $100 \%$ & 22.9 & 31 \\
\cline { 2 - 8 } & MEISTER SS100 & 28 & 7,070 & 5,370 & $94 \%$ & 23.0 & 59 \\
\cline { 2 - 8 } & MEISTER SS100 & 49 & 7,290 & 5,870 & $103 \%$ & 23.2 & 70 \\
\cline { 2 - 8 } & MEISTER SS100 & 71 & 8,100 & 6,460 & $113 \%$ & 23.4 & 74 \\
\hline \multirow{5}{*}{ Hiyokumochi } & 0 & 6,140 & 4,810 & & 22.3 & \\
\cline { 2 - 8 } & Co Fertilizer & 140 & 8,150 & 6,410 & $100 \%$ & 22.7 & 49 \\
\cline { 2 - 8 } & Conventional & 49 & 7,630 & 6,140 & $96 \%$ & 22.6 & 44 \\
\cline { 2 - 8 } & MEISTER S120 & 42 & 7,990 & 6,400 & $100 \%$ & 22.6 & 71 \\
\cline { 2 - 8 } & MEISTER S120 120 & 105 & 8,530 & 6,670 & $104 \%$ & 22.5 & 52 \\
\hline
\end{tabular}

species, releasing longevity was changed. "MEISTER" dosage was reduced three steps from the conventional.

Due to the lack of initial nitrogen from sigmoidal type of "MEISTER", culm length and number of ears were less than conventional.

Table 3 describes the result of brawn rice yield and nitrogen recovery rate. The more the dosage of "MEISTER" was applied, the more the yield was obtained. Compared to the conventional, more than $60 \%$ of "MEISTER" dosage led to the same or more yield. In addition, nitrogen recovery rate of "MEISTER" was more than twice of the conventional.

As the result, almost the same yields were obtained at three rice species by applying $60 \%$ of "MEISTER" nitrogen from the conventional, though culm length and number of ears were less than the conventional. Using "MEISTR" can reduce $40 \%$ fertilizer cost due to the cost calculation (Table 4).

3.1.1 NAEBAKOMAKASE

"MEISTER" can control its releasing precisely. 
Table 4 Comparison of fertilizer cost $\$ / ¥=110$.

\begin{tabular}{|l|l|c|c|c|}
\hline Rice Species & Treatment & $\begin{array}{l}\text { N Dosage } \\
\text { Ratio, \% }\end{array}$ & $\begin{array}{l}\text { Fertilizer } \\
\text { Cost, \$/ha }\end{array}$ & $\begin{array}{l}\text { Fertilizer } \\
\text { Cost Ratio* }\end{array}$ \\
\hline \multirow{2}{*}{ Yumeshizuku } & Conventional & 100 & 277.4 & \\
\cline { 2 - 5 } & MEISTER S100 & 60 & 171.1 & $62 \%$ \\
\hline \multirow{2}{*}{ Hinohikari } & Conventional & 100 & 507.0 & \\
\cline { 2 - 5 } & MEISTER SS100 & 60 & 285.2 & $56 \%$ \\
\hline \multirow{2}{*}{ Hiyokumochi } & Conventional & 100 & 758.5 & \\
\cline { 2 - 5 } & MEISTER S120 & 60 & 456.3 & $60 \%$ \\
\hline
\end{tabular}

* Fertilizer cost ratio: MEISTER/Conventional * 100

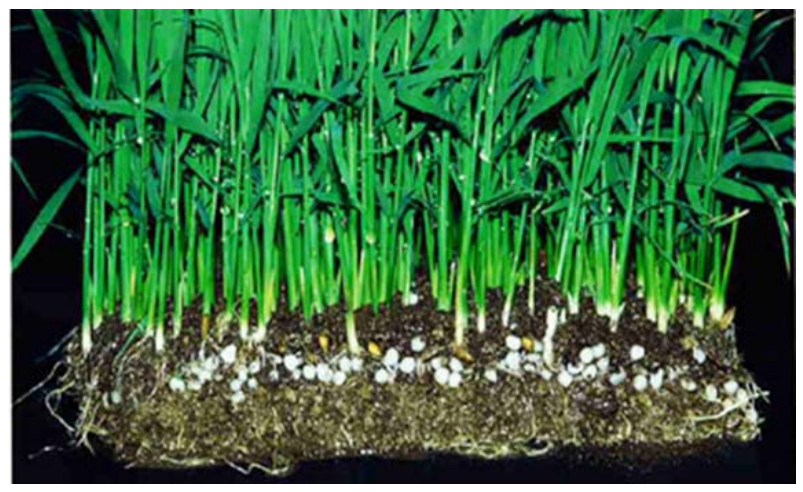

Photo 2 NAEBAKOMAKASE.

Using some kind of sigmoidal types "MEISTER", seeding can be made together with fertilization without fertilizer salt injury to the rice (Photo 2). This type of "MEISTER" can supply all the nutrients necessary for the plant to grow during the whole growing period in nursery box application, and tillage for fertilization is unnecessary. We JCAM-AGRI name this type of coated fertilizer "NAEBAKOMAKASE". This new farming method can save on other major field operations, thus reducing the costs, of rice farming. Now "NAEBAKOMAKASE" is estimated to use more than 23,000 ha rice field especially northeastern Japan (2011).

\subsection{Chinese Cabbage}

Ikeda estimated the single basal application of "MEISTER" for Chinese cabbage in Aichi prefecture Japan to reduce the nitrogen leaching from fertilizers [8]. The study was done at the Aichi agricultural research center for 2 years.
The fertilizer application dosages are in Table 5 . The basal fertilizer of conventional was normal NPK compound. The additional fertilizer was normal NK compound. Regarding to the coated urea treatment, $30 \%$ of nitrogen was applied from ammonia sulfate and Diammonium Phosphate. Remaining 70\% of nitrogen was "MEISTER". "MEISTER" was the linear type of 40 days. Multi-phosphate was used as another phosphate. Potassium sulfate and Potassium silicate were applied as potassium. In 1993, 80\% nitrogen of conventional treatment was set as the dosage reduction in "MEISTER" treatment.

Plants at the "MEISTER" treatment grew smoothly as same as one at the conventional both years. The weights at the "MEISTER" treatments were better than one at the conventional even the $20 \%$ nitrogen reduction in 1993 (Table 6).

Nitrogen recovery rate was calculated and soil analysis was done in 1993 (Table 7). Nitrogen recovery rates of "MEISTER" were $60 \%$ while that of the conventional was $54 \%$. Soil Electric Conductivity 
Table 5 Application dosage at Chinese cabbage experiment.

\begin{tabular}{|c|c|c|c|c|c|}
\hline \multirow{3}{*}{\multicolumn{2}{|c|}{ Treatment }} & \multicolumn{2}{|c|}{1992} & \multicolumn{2}{|c|}{1993} \\
\hline & & Basal (Kg/ha) & Additional $(\mathrm{Kg} / \mathrm{ha})$ & Basal (Kg/ha) & Additional ( $\mathrm{Kg} / \mathrm{ha})$ \\
\hline & & $\mathrm{N}-\mathrm{P} 205-\mathrm{K} 20$ & $\mathrm{~N}-\mathrm{P} 2 \mathrm{O} 5-\mathrm{K} 2 \mathrm{O}$ & $\mathrm{N}-\mathrm{P} 2 \mathrm{O} 5-\mathrm{K} 2 \mathrm{O}$ & $\mathrm{N}-\mathrm{P} 2 \mathrm{O} 5-\mathrm{K} 2 \mathrm{O}$ \\
\hline No Nitrog & & - & - & $0-250-350$ & - \\
\hline Conventio & & $150-250-150$ & $200-0-200$ & $150-250-150$ & $200-0-200$ \\
\hline MEISTER & Standard & $350-250-350$ & - & $350-250-350$ & - \\
\hline L40 & Reduction & - & - & $280-250-350$ & - \\
\hline
\end{tabular}

Table 6 Yield of Chinese cabbage experiment.

\begin{tabular}{|c|c|c|c|c|c|}
\hline \multirow{3}{*}{\multicolumn{2}{|c|}{ Treatment }} & \multicolumn{2}{|c|}{1992} & \multicolumn{2}{|c|}{1993} \\
\hline & & Head Weight & Exite Weight & Head Weight & Exite Weight \\
\hline & & $\mathrm{kg} /$ Stump & $\mathrm{kg} /$ Stump & $\mathrm{kg} /$ Stump & $\mathrm{kg} /$ Stump \\
\hline \multicolumn{2}{|c|}{ No Nitrogen } & - & - & 0 & 0.23 \\
\hline \multicolumn{2}{|c|}{ Conventional } & 2.47 & 0.95 & 2.11 & 0.77 \\
\hline \multirow{2}{*}{\begin{tabular}{|l|} 
MEISTER \\
L40
\end{tabular}} & Standard & 2.52 & 0.96 & 2.47 & 1.03 \\
\hline & Reduction & - & - & 2.29 & 0.83 \\
\hline
\end{tabular}

Table 7 Nitrogen recovery rate and soil analysis (1993).

\begin{tabular}{|c|c|c|c|c|}
\hline \multicolumn{2}{|l|}{ Treatment } & $\begin{array}{l}\text { N Recovery } \\
\text { Rate.\% }\end{array}$ & $\operatorname{EC}(1: 2.5)$ & $\begin{array}{l}\mathrm{NO3}-\mathrm{N}, \\
\mathrm{mg} / 100 \mathrm{~g}\end{array}$ \\
\hline \multicolumn{2}{|c|}{ Conventional } & 54.1 & 0.45 & 2.51 \\
\hline \multirow{2}{*}{$\begin{array}{l}\text { MEISTER } \\
\text { L40 }\end{array}$} & Standard & 60.7 & 0.05 & 0.73 \\
\hline & Reduction & 60.3 & 0.07 & 0.49 \\
\hline
\end{tabular}

Table 8 Application dosage at long onion experiment.

\begin{tabular}{|c|c|c|c|c|c|c|}
\hline & Basal (Kg/ha) & \multicolumn{3}{|c|}{ Additional $(\mathrm{Kg} / \mathrm{ha})$} & Total(kg/ha) \\
\hline & & $\mathrm{N}-\mathrm{P} 205-\mathrm{K} 2 \mathrm{O}$ & $\mathrm{N}-\mathrm{P} 205-\mathrm{K} 2 \mathrm{O}$ & $\mathrm{N}-\mathrm{P} 2 \mathrm{O} 5-\mathrm{K} 2 \mathrm{O}$ & $\mathrm{N}-\mathrm{P} 205-\mathrm{K} 2 \mathrm{O}$ & $\mathrm{N}-\mathrm{P} 205-\mathrm{K} 2 \mathrm{O}$ \\
\hline \multicolumn{2}{|l|}{ Treatment } & 150 & $30-0-0$ & $30-0-0$ & $30-0-0$ & $240-150-150$ \\
\hline \multirow{2}{*}{ MEISTER } & & & 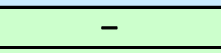 & - & - & $160-150-150$ \\
\hline & L30:S & $160-150-150$ & - & - & - & $160-150-150$ \\
\hline
\end{tabular}

Table 9 Yield and recovery rate.

\begin{tabular}{|c|c|c|c|c|}
\hline Treatmen & & Yield $(\mathrm{Kg} / \mathrm{ha})$ & Yield Ratio & N Recovery Rate, $\%$ \\
\hline Conventic & & 56,300 & $100 \%$ & 42 \\
\hline LMEISTED & $L 30: S 60=1: 3$ & 58,800 & $104 \%$ & 66 \\
\hline | MIEIS IER & L30:S 100 $=1: 3$ & 55,000 & $98 \%$ & 56 \\
\hline
\end{tabular}

(EC) and nitrate nitrogen at the "MEISTER" treatments were less than those at the conventional.

\subsection{Long Onions}

Murakami studied one time basal application for a long onion by using a local fertilizing machine with planting trench in Akita prefecture Japan [9].

The fertilizer application dosages are in Table 8 . The conventional nitrogen, phosphate and potash were normal rapid soluble fertilizers. The total nitrogen at the conventional was $240 \mathrm{~kg} / \mathrm{ha}$. On the other hand, there were two "MEISTER" treatments to find the suitable longevity. One was applied with the linear type of 40-day (40 N kg/ha) and the sigmoidal type of 60-day $(120 \mathrm{~N} \mathrm{~kg} / \mathrm{ha})$. Another was applied with the linear type of 40-day (40 N kg/ha) and the sigmoidal type of 100-day (120 N kg/ha).

Table 9 describes the result of yield and nitrogen 
recovery rate. Applying the sigmoidal 100-day type led to being good at the $\mathrm{N}$ recovery but not so good at the yield comparing with the conventional. On the other hand, the sigmoidal 60-day type was better at the $\mathrm{N}$ recovery and yield than the conventional. This means the sigmoidal 100-day type is a little bit long longevity for growth of long onion and the sigmoidal 60-day type is suitable for the long onion in this area.

\section{Conclusion}

Coated fertilizer like "MEISTER" is a kind of thermoplastic resin coated fertilizer whose release of nutrients is mainly determined by temperature. This type of coated fertilizers shows accurate release control of nutrient. The use of coated fertilizers brings some merits for agriculture as follows.

(a) Efficient use of fertilizer resources

Coated fertilizers can supply all the nutrients in a pattern synchronizing the demand of the plants during the whole growing period. High recovery of coated fertilizer is obtained at the field. This makes the reduction of fertilizer application dosage and save the fertilizer resources.

(b) Reduction of environment load by fertilizer

Normal soluble chemical fertilizers are known to be contributing to serious problems of environmental pollution such as salt accumulation, nitrate contamination of underground and surface water by leaching and running off, and increasing in nitrous oxide in the air by denitrification. The controlled release of nutrient from coated fertilizers and synchronized uptake of nutrient by crops could reduce these environmental loads by fertilizer application. Coated fertilizers are definitely environmental friendly fertilizers.

(c) Labor saving

Single basal application can cut the additional applications. This reduces the labor cost. Recently, rapid decreases in agricultural population and rapid aging of farmers have continued in Japan. This trend will occur in other countries near future. Using coated fertilizers is one of the measurements to solve the labor shortage in agriculture. Actually, coated fertilizers are widely used for paddy rice, upland crops and horticultural plants in Japan.

Thus applying coated fertilizers is really smart fertilization technology in agriculture.

Coated fertilizers seem to closely meet the requirements of an ideal fertilizer. But the problem is its high price compared to the normal fertilizers. Though coated fertilizers are popular for many crops in Japan, there is a limitation to apply coated fertilizers in the world especially developing countries. We think one of the reasons is the high price of coated fertilizers. Unit price of coated fertilizer is expensive on the surface, though total cost of applying coated fertilizers is often cheaper than one of rapid soluble fertilizers. This sometimes disturbs the spread of coated fertilizers. So, we have been trying to make an effort to reduce production cost and application enlargement trial in many countries for becoming widespread. Through those studies and development, we believe coated fertilizers will contribute to agriculture in the world.

\section{Remarks}

Main of this paper was printed as the proceeding of FFTC (Food and Fertilizer Technology Center for Asian and Pacific Region) wark shop in 2018.

\section{References}

[1] Trenkel, M. E. 2010. Slow and Controlled-Release and Stabilized Fertilizers: An Option for Enhancing Nutrient Use Efficiency in Agriculture. Paris, France: International Fertilizer Industry Association.

[2] Fujita, T., Maeda, S., Shibata, M., and Takahashi, T. 1989. "Research and Development of Coated Fertilizer." In Proceedings of Symposium on Fertilizers-Present and Future, Japanese Society of Soil Science and Plant Nutrition, 111-26.

[3] Anonymous. 2017. Pocket Fertilizer Hand Book. Association of Agriculture and Forestry Statics Japan, 7-8.

[4] Anonymous. 2009. Current Status and Issues of Fertilizer Application in Rice Cultivation in Japan. Ministry of 
Agriculture, Forestry and Fisheries Japan.

[5] Shoji, S., and Gandeza, A. T. 1992. Controlled Release Fertilizers with Polyolefin Resin Coating. Sendai, Japan: Konno Printing Co. Ltd.

[6] Kaneda, Y. 1995. "Innovation of Fertilizer Application by Using Controlled Release Fertilizers. 2. The Single Application of Fertilizer in Nursery Box to Non Tillage Transplanted Rice.” Japanese Journal of Soil Science and Plant Nutrition 66: 176-81.
[7] Otsuka, N. 2018. "Labor Saving and Low Cost Fertilizer Application Method for Rice by Using Only Coated Urea at Co-Suit." Agriculture and Science 703: 7-13.

[8] Ikeda, A. 1994. "Oneshot Application for a Chinese Cabbage by Using Coated Urea." Agriculture and Science 442: 1-4.

[9] Murakami, A. 2005. "One Shot Application for a Long Onion by Using Local Fertilizing Machine with Planting Trench." Green Report 428: 4-5. 